Please do not remove this page

RMIT

UNIVERSITY

\title{
The damping of gypsum plaster board wooden stud cavity walls
}

Davy, John; Phillips, Timothy; Pearse, John

https://researchrepository.rmit.edu.au/esploro/outputs/9921862112201341/filesAndLinks?institution=61RMIT_INST\&index=null

Davy, J., Phillips, T., \& Pearse, J. (2014). The damping of gypsum plaster board wooden stud cavity walls. Applied Acoustics, 88, 52-56. https://doi.org/10.1016/j.apacoust.2014.08.006

Document Version: Accepted Manuscript

Published Version: https://doi.org/10.1016/j.apacoust.2014.08.006

Repository homepage: https://researchrepository.rmit.edu.au

(C) 2015 Elsevier Ltd

Downloaded On 2023/04/27 00:58:33 +1000

Please do not remove this page 
Thank you for downloading this document from the RMIT Research Repository.

The RMIT Research Repository is an open access database showcasing the research outputs of RMIT University researchers.

RMIT Research Repository http://researchbank.rmit.edu.au/

\section{Citation:}

Davy, J, Phillips, T and Pearse, J 2014, 'The damping of gypsum plaster board wooden stud cavity walls', Applied Acoustics, vol. 88, pp. 52-56.

See this record in the RMIT Research Repository at:

https://researchbank.rmit.edu.au/view/rmit:29959

Version: Accepted Manuscript

Copyright Statement: (C) 2015 Elsevier Ltd

Link to Published Version:

http://dx.doi.org/10.1016/j.apacoust.2014.08.006 
The damping of gypsum plaster board wooden stud cavity walls

John Laurence Davy ${ }^{\mathrm{a}, \mathrm{b},{ }^{*}}$, Timothy J. Phillips ${ }^{\mathrm{c}}{ }^{\mathrm{J}}$ ohn R. Pearse ${ }^{\mathrm{c}}$

${ }^{a}$ School of Applied Sciences, RMIT University, GPO Box 2476V Melbourne, Victoria 3001, Australia,john.davy@,rmit.edu.au

${ }^{b}$ CSIRO Materials Science and Engineering, PO Box 56 Highett Victoria 3190, Australia, john.davy@csiro.au

${ }^{c}$ University of Canterbury, Mechanical Engineering, Private Bag 4800, Christchurch 8140, New Zealand, tjnphillips@,gmail.com,john.pearse@canterbury.ac.nz

*Corresponding author. Tel.: +61422171812; fax: +61399255290. E-mail address:

john.davy@,rmit.edu.au (J. L. Davy)

\section{ABSTRACT}

Published test reports on the sound insulation of gypsum plaster board cavity stud walls with viscoelastic glue sandwiched between two layers of gypsum plaster board working as a constrained layer damper show large increases in sound insulation compared to the sound insulation of the same wall without the viscoelastic material. An increase in the sound insulation would be expected above the critical frequency of the gypsum plaster board panels and in the vicinity of the mass-air-mass resonant frequency due to the increased damping. However the test results show significant increases at other frequencies as well. A critical examination of the theory shows that the sound transmission via the air in the wall cavity is not expected to be greatly affected by the damping at these other frequencies. On the other hand, the sound transmission via the studs is affected at all frequencies by the damping. Hence it is not surprising that the published results are all for cavity stud walls. The sound insulation of two $16 \mathrm{~mm}$ thick gypsum plaster board sheets was measured. The sheets were mounted touching each other in three different configurations. These were without glue in between, bonded together with viscoelastic glue and spot bonded together with standard commercial glue. Surprisingly the elastic material compound gave better results even below the critical frequency, although the improvement became smaller and then disappeared as the frequency was decreased. A cavity stud wall with the second and third of the above configurations on each side of the studs was also tested. Again the viscoelastic glue performed better than the standard commercial glue, but the viscoelastic results were less than the original published results. Further published results were found which were in between the original published results and the experimental results obtained by the authors of this paper.

Keywords: Sound insulation, sound transmission loss, damping loss factor, cavity stud wall, gypsum plaster board, viscoelastic damping

\section{Introduction}


Test reports published on the internet show that sound insulation of walls, with two layers of $16 \mathrm{~mm}$ thick gypsum plaster board on each side of 90 by $45 \mathrm{~mm}$ wooden studs with sound absorbing material in the air cavity, can be improved if a viscoelastic glue compound, such as Green Glue noise proofing compound or QuietGlue Pro, is sandwiched between the two layers of gypsum plaster board. An examination of the theory [1, 2] shows that an increase in the sound insulation is expected in the region of and above the critical frequencies of the wall leaves if the damping loss factor of the wall leaves is increased for both transmission via the air cavity and transmission via the studs and screws. Below the critical frequency, only the sound insulation due to transmission via the studs and screws is expected to be increased by an increased damping loss factor. This explains why the published test reports are only for stud walls. Increasing the damping loss factor is expected to also increase the sound insulation of a cavity stud wall in the vicinity of the normal incidence mass-air-mass resonant frequency.

Table 1. The damping loss factor $(\eta)$ and the Young's modulus $(E)$ which makes theory best agree with experiment.

\begin{tabular}{|c|c|c|c|c|c|c|}
\hline Specimen & Leaves $(\mathrm{mm})$ & Glue & $\begin{array}{c}\text { Screw } \\
\text { Spacing } \\
(\mathrm{mm})\end{array}$ & $\begin{array}{c}\text { Number } \\
\text { of wall } \\
\text { leaves }\end{array}$ & $\eta$ & $\begin{array}{c}E \\
(\mathrm{GPa})\end{array}$ \\
\hline UCSNO & $16+16$ & Nothing & 305 & 1 & 0.060 & 1.1 \\
\hline UCSISR & $16+16$ & ISR70-03 & 305 & 1 & 0.060 & 0.95 \\
\hline UCSGG & $16+16$ & GreenGlue & 305 & 1 & 0.20 & 0.85 \\
\hline UCDISR & $2 \times(16+16)$ & ISR70-03 & 305 & 2 & 0.034 & 0.87 \\
\hline UCDGG & $2 \times(16+16)$ & GreenGlue & 305 & 2 & 0.081 & 1.4 \\
\hline OL05DNO & $2 \times(16+16)$ & Nothing & 305 & 2 & 0.030 & 0.76 \\
\hline OL05DGG & $2 \times(16+16)$ & GreenGlue & 305 & 2 & 0.27 & 0.73 \\
\hline OL05DGGM & $2 \times(16+16)$ & GreenGlue & 406 & 2 & 0.33 & 0.73 \\
\hline NRDNO & $2 \times(16+16)$ & Nothing & 305 & 2 & 0.024 & 0.74 \\
\hline NRDGG & $2 \times(16+16)$ & GreenGlue & 305 & 2 & 0.12 & 0.80 \\
\hline OL08DGG & $2 \times(16+16)$ & GreenGlue & 305 & 2 & 0.17 & 0.72 \\
\hline OL10DGG & $2 \times(16+16)$ & GreenGlue & 305 & 2 & 0.14 & 0.67 \\
\hline OL11DGG & $2 \times(16+16)$ & GreenGlue & 305 & 2 & 0.16 & 0.74 \\
\hline OL06DQG & $2 \times(16+16)$ & QuietGlue & 305 & 2 & 0.10 & 0.73 \\
\hline OL08DQGPA & $(13+13)+(16+16)$ & QuietGluePro & 305 & 2 & 0.23 & 0.76 \\
\hline OL11DQGPA & $(13+13)+(16+16)$ & QuietGluePro & 305 & 2 & 0.25 & 1.06 \\
\hline OL05DGGA & $(13+13)+(16+16)$ & GreenGlue & 305 & 2 & 0.30 & 0.71 \\
\hline OL05DGGAN & $(13+13)+(16+16)$ & GreenGlue & 406 & 2 & 0.30 & 0.70 \\
\hline
\end{tabular}

\section{The measurements}

First the measurement naming system is described. The measurements used in this paper were made either at the University of Canterbury (UC), at Orfield Laboratories (OL) or at the National Research Council of Canada (NR). Because the same wall constructions were measured at Orfield Laboratories in different years, the OL is followed by the last two digits of the year. This paper describes measurements on single (S) and double (D) leaf walls. Each 
wall leaf normally consisted of two layers of $16 \mathrm{~mm}$ gypsum plaster board. Some of the double leaf walls had two layers of $13 \mathrm{~mm}$ gypsum plaster board rather than two layers of 16 $\mathrm{mm}$ gypsum plaster board for the second wall leaf. This is indicated by use of the letter (A). There was either nothing (NO), spots of Simson ISR 70-03 Elastic Glue (ISR) applied on a 0.25 by $0.2 \mathrm{~m}$ grid, Green Glue noise proofing glue (GG) applied as described by the manufacturer, QuietGlue (QG) or QuietGlue Pro (QGP). The double leaf walls were on 90 by $45 \mathrm{~mm}$ wooden studs at $0.61 \mathrm{~m}$ centres. The inner layer of gypsum plaster board was screwed to the wooden studs at $0.61 \mathrm{~m}$ centres. The outer layer of gypsum plaster board was screwed to the wooden studs at $0.305 \mathrm{~m}$ centres. For one wall this spacing was $0.203 \mathrm{~m} \mathrm{(M)}$ and for another wall this spacing was $0.406 \mathrm{~m}(\mathrm{~N})$. The theoretical predictions are prefixed with $(\mathrm{P})$. The double leaf walls contained sound absorbing material in their wall cavities. The wall specimens tested are shown in Table I.

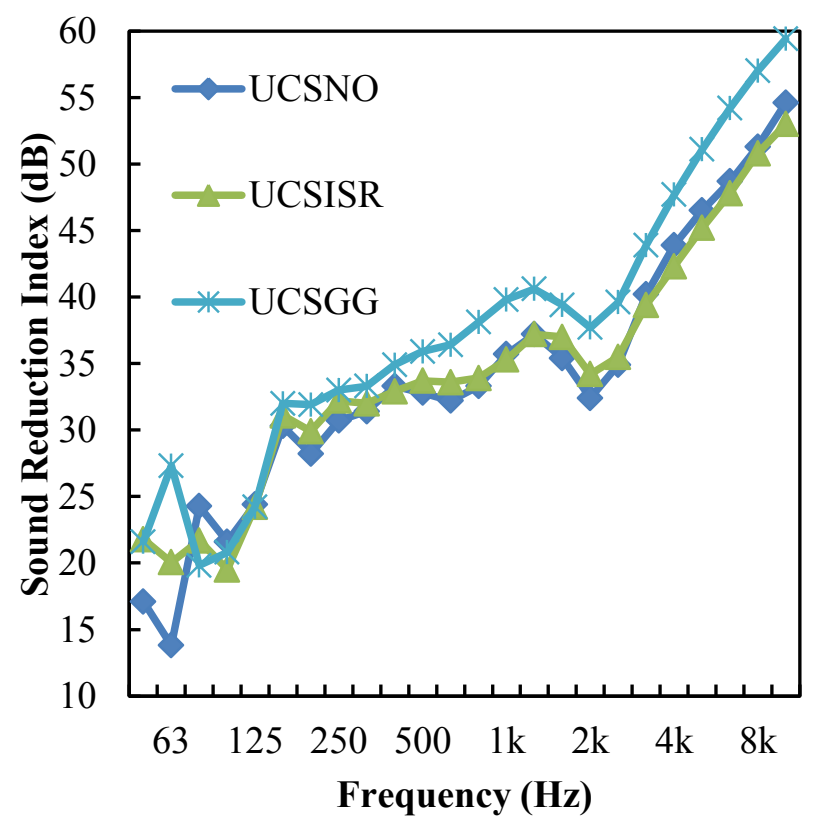

Figure 1. The measured sound insulation of three single leaf walls with or without Green Glue.

The sound insulation measurements on the double leaf walls tested at Orfield Laboratories (OL) $[3,4]$ were made using the pressure-pressure technique [5]. The wall specimens had an area of $5.99 \mathrm{~m}^{2}$. The source and receiving rooms had volumes of 117.5 and $234.5 \mathrm{~m}^{3}$ respectively. Some of measurements were within $10 \mathrm{~dB}$ of the laboratory's stated flanking transmission limit. Thus the actual sound insulation "may be higher than measured" because "the result may be potentially limited by the laboratory due to flanking transmission around the specimen". For some of the measurements, the signal to noise ratio in the receiving room was less than $5 \mathrm{~dB}$ for the frequencies from 6.3 to $10 \mathrm{kHz}$. Thus the actual sound insulation of these wall specimens "may be higher than measured" in this frequency range. The results are "an estimate of the lower limit". The wall leaves in the wall specimens measured by Orfield Laboratories had surface densities of about $22 \mathrm{~kg} / \mathrm{m}^{2}$. 
The sound insulation measurements at the University of Canterbury (UC) were made using the pressure-intensity technique [6] except for the fact that the specimens were smaller than allowed by [6]. The volume of the reverberant sending room was $215.8 \mathrm{~m}^{3}$. The receiving room was a semi-anechoic room. The opening for the single leaf (S) wall specimens measured 1.546 by $0.946 \mathrm{~m}$ giving a specimen area of $1.463 \mathrm{~m}^{2}$. The opening for the double leaf (D) wall specimens was 1.932 by $1.090 \mathrm{~m}$ giving a specimen area of $2.106 \mathrm{~m}^{2}$. Because the opening for the double leaf walls was only $1.090 \mathrm{~m}$, two central studs spaced on $0.61 \mathrm{~m}$ centres were used. This meant that the two edge studs were only about $0.2 \mathrm{~m}$ from one of the central studs. The two edge studs and the two central studs means that the effective stud spacing is only about $1.09 / 4=0.27 \mathrm{~m}$. This will give increased sound transmission via the studs due to the smaller stud spacing. The increased resonant radiation efficiency below the critical frequency due to the smaller specimen size will also give increased sound transmission below the critical frequency. On the other hand, the decreased forced radiation efficiency below and at the critical frequency due to the small specimen size means that the single leaf (S) wall specimens will have higher sound insulation. The wall leaves in the wall specimens measured by the University of Canterbury used Winstone Wallboards GIB Fyreline gypsum plaster board and had surface densities of about $27.5 \mathrm{~kg} / \mathrm{m}^{2}$.

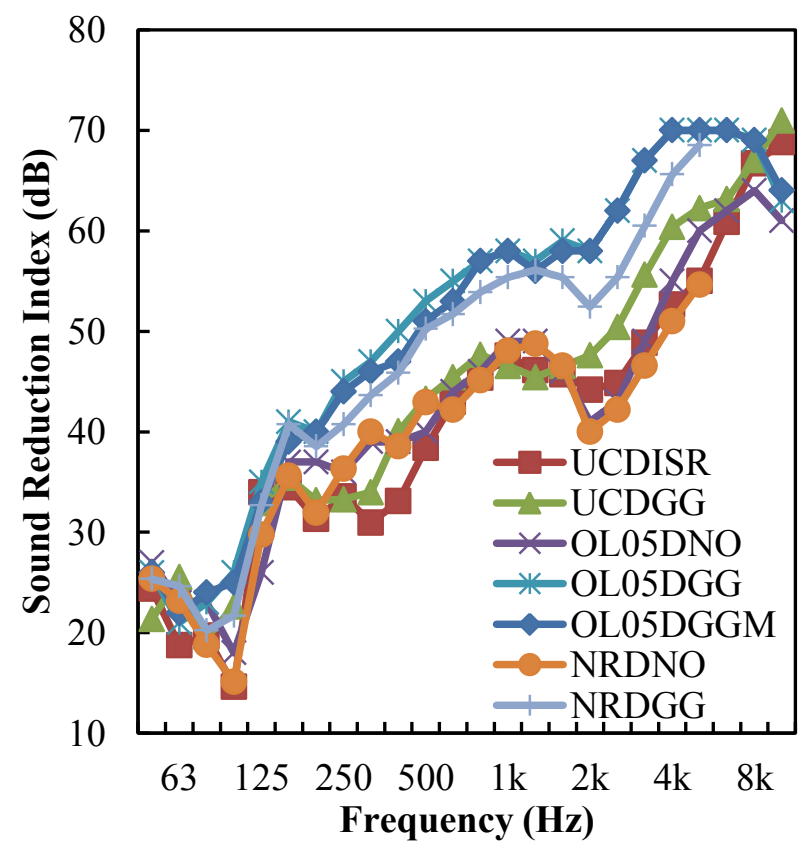

Figure 2. The measured sound insulation of seven cavity stud walls with or without Green Glue.

The sound insulation measurements on the double leaf walls tested at the National Research Council of Canada (NR) [7] were made using the pressure-pressure technique [5]. The wall specimens had an area of $8.64 \mathrm{~m}^{2}$. The reverberation rooms had volumes of 145 and $250 \mathrm{~m}^{3}$.

Figure 1 shows the sound insulation of the three single leaf walls which were measured at the University of Canterbury. The sound insulation of the Green Glue wall was greater than the sound insulation of the walls with no glue and with the ISR glue at all frequencies at and 
above $160 \mathrm{~Hz}$. This was expected to occur above the critical frequency, but it was a surprise that it also occurred below the critical frequency.

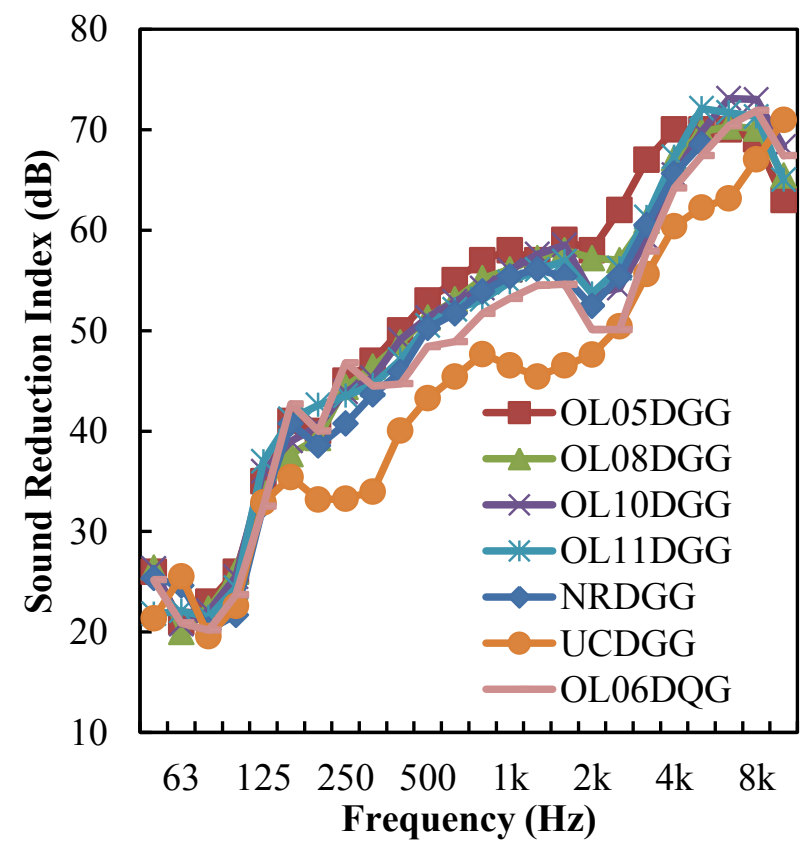

Figure 3. The measured sound insulation of six walls with Green Glue and one wall with QuietGlue.

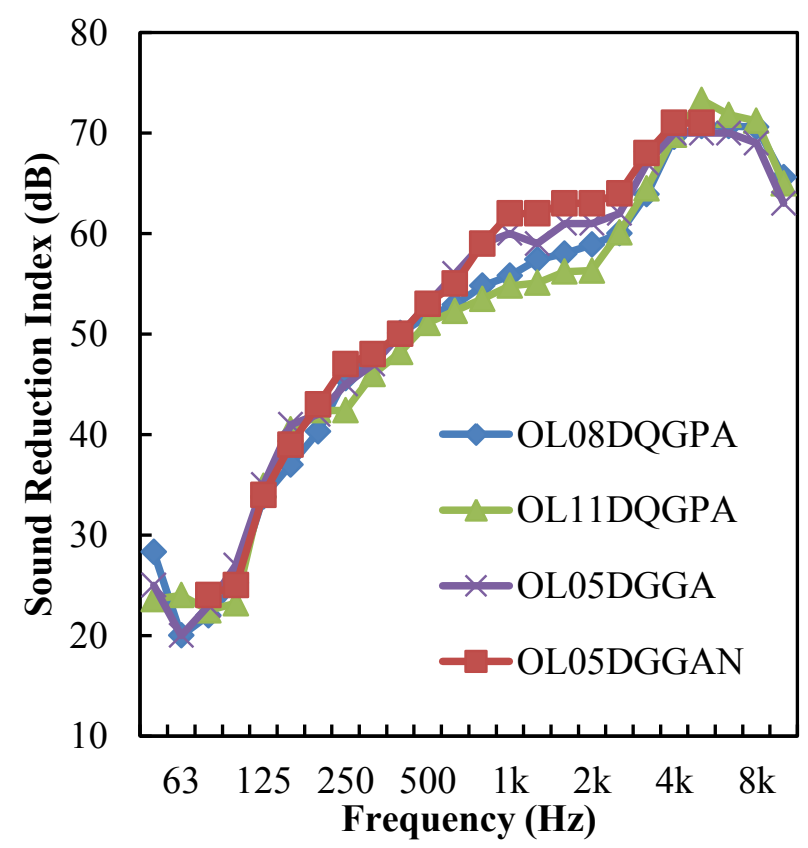

Figure 4. The measured sound insulation of two cavity stud walls with Green Glue and two cavity stud walls with QuietGlue Pro. One of the wall leaves consists of two layers of $13 \mathrm{~mm}$ gypsum plaster board and the other is two layers of $16 \mathrm{~mm}$ gypsum plaster board.

Figure 2 compares the sound insulation of seven double leaf cavity walls with and without Green Glue. The three walls with Green Glue which were measured at Orfield Laboratories $[3,4]$ and at the National Research Council of Canada [7] have higher sound insulation than 
the other four walls from $160 \mathrm{~Hz}$ to $8 \mathrm{kHz}$. The National Research Council of Canada Green Glue results lie in between the Orfield Laboratories 2005 and the University of Canterbury Green Glue results from 1.6 to $5 \mathrm{kHz}$. The University of Canterbury Green Glue wall has higher sound insulation than the University of Canterbury ISR glue wall from 315 to $800 \mathrm{~Hz}$ and from 1.6 to $8 \mathrm{kHz}$. However the increase in sound insulation is much less than in the case of the Orfield Laboratories and National Research Council of Canada measurements on larger wall specimens.

Figure 3 compares measurements of six cavity stud walls with Green Glue and one cavity stud wall with QuietGlue [3, 4]. Over much of the frequency range, four of the measurements on Green Glue walls are fairly similar and in between the Orfield Laboratories 2005 and the University of Canterbury measurements on cavity stud walls with Green Glue. Over a fair part of the frequency range, the QuietGlue measurement is less than the other Green Glue measurements apart from the University of Canterbury measurement.

Figure 4 compares the sound insulation of cavity stud walls with Green Glue or QuietGluePro $[3,4]$. One of the wall leaves consists of two layers of $13 \mathrm{~mm}$ gypsum plaster board while the other wall leaf is the same as the normal wall leaves in this paper, namely two layers of 16 mm gypsum plaster board. The Green Glue performs slightly better than the QuietGlue Pro in these measurements.

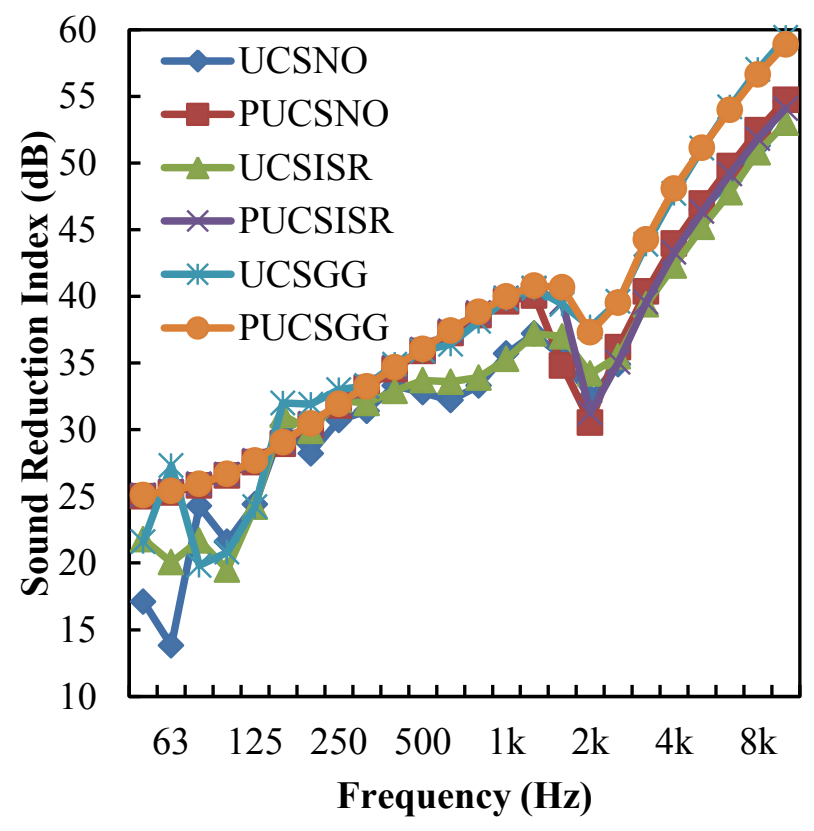

Figure 5. Measured and predicted sound insulation of three single leaf walls.

\section{Theoretical analysis}

The sound insulation of the measured walls was predicted using the theories of Davy [1, 2, 8]. One reason for this approach was that the differing sizes of the wall specimens could be taken into account. The Young's moduli and the damping loss factors of the walls were altered to give the best agreement between theory and experiment. The Young's moduli $(E)$ and the damping loss factors $(\eta)$ obtained using these procedures are shown in Table 1 . The 
damping loss factors of 0.024 and 0.030 obtained from the data for the double leaf walls without any glue is similar to the value of 0.030 used previously by the first author. It is also similar to the value of 0.034 obtained from the data for the double leaf wall with the spots of ISR glue. This value may be slightly higher because of the effect of the ISR glue. However the value of 0.060 obtained from the two single leaf walls without Green Glue is double that used previously by the first author.

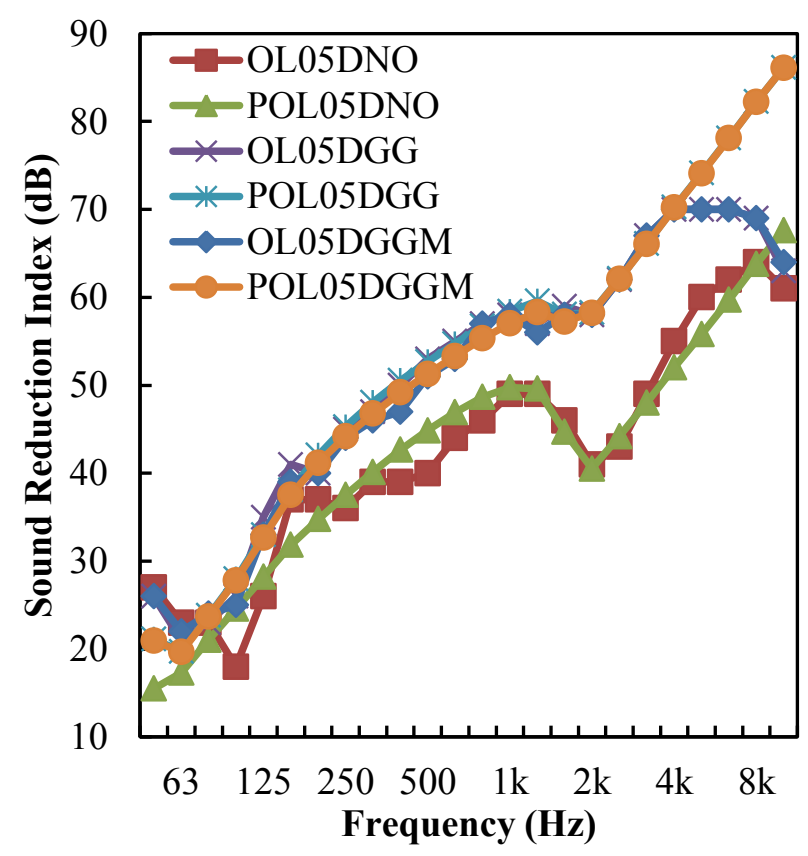

Figure 6. Comparison of theory and experiment for the Orfield Laboratories 2005 measurements on three cavity stud walls.

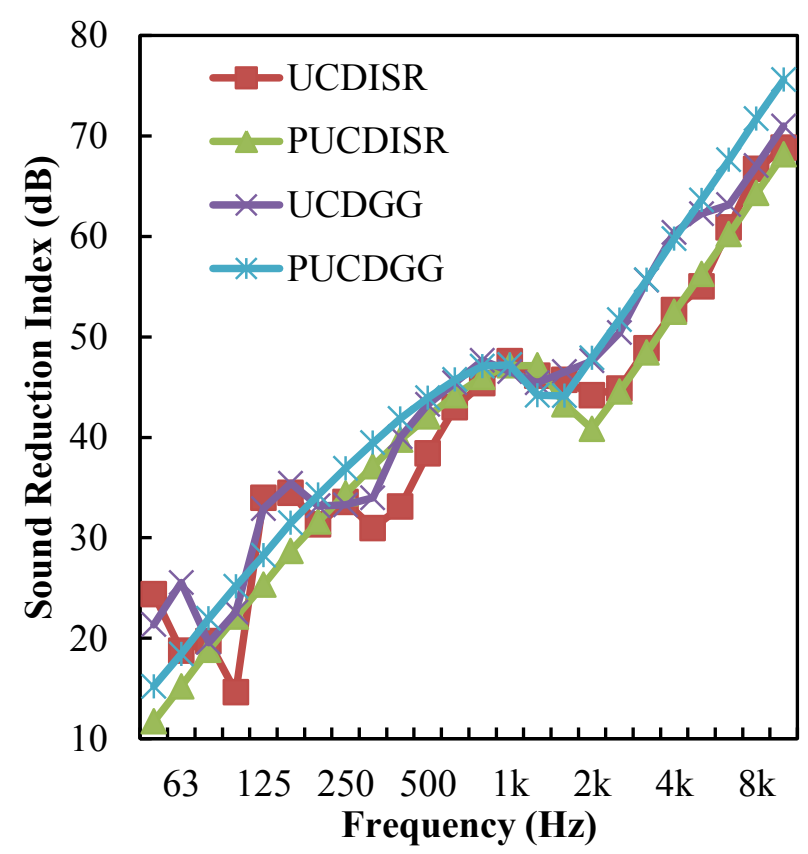

Figure 7. Comparison of theory and experiment for the University of Canterbury measurements on two cavity stud walls. 
The Orfield Laboratories 2005 double leaf Green Glue values are 0.27 and 0.33 for the standard wall case of two layers of $16 \mathrm{~mm}$ gypsum plaster board on each side of the studs and 0.30 and 0.30 when the two layers of gypsum plaster board on one side of the studs are each only $13 \mathrm{~mm}$ thick. The damping loss factor obtained at the University of Canterbury from the single leaf wall with Green Glue was 0.20. The Orfield Laboratories double leaf wall measurements in 2008, 2009 and 2010 gave 0.17, 0.14 and 0.16. The National Research Council of Canada double leaf Green Glue value was 0.12 and the double leaf wall with Green Glue measured at the University of Canterbury was only 0.081 . The sound insulation of the double stud cavity leaf walls increases as the damping loss factor increases. This has also been shown by the National Research Council of Canada [7]. The QuietGlue measurements gave 0.10, which was at the low end of the Green Glue values. The two QuietGlue Pro values were 0.23 and 0.25 on a wall with two layers of $13 \mathrm{~mm}$ gypsum plaster board replacing the two layers of $16 \mathrm{~mm}$ gypsum plaster board on one side of the studs. These values are in the middle of the range of Green Glue values. The range of Green Glue damping loss factors was a surprise. It applies that there is a fair degree of natural variation.

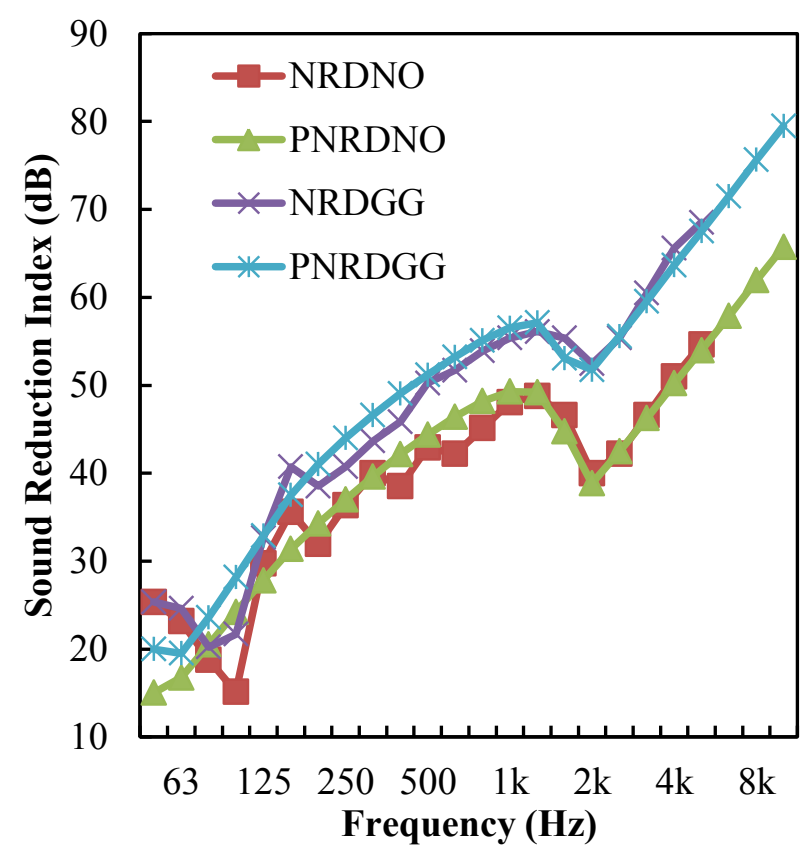

Figure 8. Comparison of theory and experiment for the National Research Council of Canada measurements on two cavity stud walls.

The measured and predicted sound insulation of the single leaf walls is shown in Figure 5. Below about half of the critical frequency, the theoretical predictions are almost the same. They also agree very well with the measured values for the wall with Green Glue in this frequency range down to about $160 \mathrm{~Hz}$. Thus the reason for the difference between the single leaf walls with and without Green Glue below the critical frequency is that the measurements on the walls without Green Glue do not agree with the theoretical predictions in the frequency range from 500 to $1250 \mathrm{~Hz}$. The reason for this disagreement is not known. Above the critical frequency, the difference in the sound insulation of the walls with and without Green Glue is due to the difference in damping loss factors. It should be noted that the sound 
insulation curves of the single leaf walls are slightly curved above the critical frequency because of Heckl and Donner's shearing correction [8]. This correction is of the order of -5 $\mathrm{dB}$ at $10 \mathrm{kHz}$.

Figure 6 shows the comparison of theory and experiment for the 3 cavity stud walls that were measured at Orfield Laboratories in 2005 on the standard wall cavity wall configuration used in this paper. The theory is in very good agreement with the measurements on the two cavity stud walls with Green Glue in the frequency range from $80 \mathrm{~Hz}$ to $4 \mathrm{kHz}$. Above $4 \mathrm{kHz}$, the Orfield Laboratories' measurements have clearly been affected by background noise and flanking transmission as indicated in their test reports. The theory predicts that sound insulation of the wall with the $305 \mathrm{~mm}$ screw spacing should be $1.8 \mathrm{~dB}$ greater than the wall with $203 \mathrm{~mm}$ screw spacing. The average experimental difference between these two walls from $100 \mathrm{~Hz}$ to $1.6 \mathrm{kHz}$ is $1.2 \mathrm{~dB}$. The experimental difference from 2 to $8 \mathrm{kHz}$ is $0 \mathrm{~dB}$. These differences of 0.6 and $1.8 \mathrm{~dB}$ between the theoretical and experimental diffrences is the reason why the calculated damping loss factors for these two walls differ by $0.9 \mathrm{~dB}$.

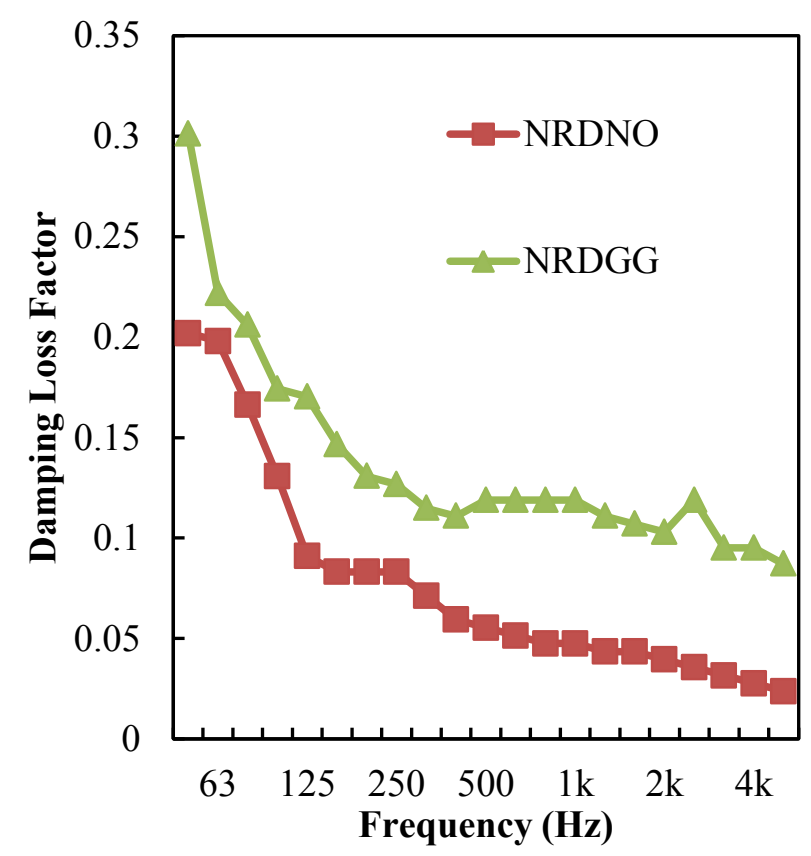

Figure 9. The damping loss factor of two cavity stud walls measured by the National Research Council of Canada.

The theory is in reasonable agreement with the measurement on the cavity stud wall without Green Glue from $125 \mathrm{~Hz}$ to $8 \mathrm{kHz}$. The measurement at $10 \mathrm{kHz}$ is affected by background and/or flanking. As was the case with the single leaf walls, the application of Green Glue makes the experimental results agree better with the theoretical predictions.

Figure 7 shows the comparison between theory and experiment for the two cavity stud walls measured at the University of Canterbury. The agreement between theory and experiment below the critical frequency is not as good as that for the larger lateral extent cavity stud wall specimens measured at the other two laboratories. Above the critical frequency the agreement 
between theory and experiment is good, apart from the fact that the experimental Green Glue results tend to the ISR glue results in the 6.3 to $10 \mathrm{kHz}$ range.

Figure 8 shows the comparison between theory and experiment for the two National Research Council of Canada cavity stud wall results. The theory is in reasonable agreement with the experimental results above $125 \mathrm{~Hz}$. The other specimens described in this report also had their experimental and theoretical results compared in order to obtain the values of Young's moduli and damping loss factors given earlier in this paper. The comparisons between theory and experimental were similar to the comparison already given and thus have not been included in this paper.

Figure 9 shows the damping loss factor for cavity stud walls with and without Green Glue as a function of frequency. The results were measured by the National Research Council of Canada [9] using structural reverberation time. The average values of the damping loss factor from $200 \mathrm{~Hz}$ to $5 \mathrm{kHz}$ for the wall without and with Green Glue were 0.05 and 0.11 . The values obtained from the sound insulation measurements at the National Research Council of Canada were 0.024 and 0.12. The values for the wall with Green Glue are in good agreement. This supports the method of calculating the damping loss factor from the sound insulation data. The values for the wall without Green Glue are not in such good agreement, although the $5 \mathrm{kHz}$ value was 0.024 .

\section{Discussion}

The large improvement in the sound insulation measured at Orfield Laboratories and at the National Research Council of Canada of cavity stud walls with sound absorbing material in their cavity when Green Glue was used between sheets of gypsum plaster board was a surprise. However, the fact that theory can explain these increases as being due to large increases in the damping loss factor of the sheets of gypsum plaster board means that the results seem reasonable.

The damping loss factors deduced from the measurement of the sound insulation of a single leaf gypsum plaster board wall with Green Glue were in between those deduced from Orfield Laboratories 2005 measurements and National Research Council of Canada measurements of the sound insulation of cavity stud walls with Green Glue. However the damping loss factors deduced from the single leaf walls without Green Glue were about double what the first author had previous obtained and about double the damping loss factors deduced from the cavity stud walls without Green Glue. The damping loss factor indicated by the sound insulation measurements at the University of Canterbury of the cavity stud wall with Green Glue was less than the National Research Council of Canada result which was in turn less than the Orfield Laboratories 2005 results. The later Orfield Laboratories results were in between their 2005 results and the National Research Council of Canada results. There can be significant variation in the damping loss factor produced by Green Glue. The QuietGlue and the QuietGlue Pro were slightly lower than the corresponding Green Glue results apart from the University of Canterbury double leaf cavity stud wall Green Glue results. 
The larger number of screw connections per unit area and the smaller size of the University of Canterbury sample were taken into account by the theory. The Green Glue is believed to have been installed according the manufacturer's instructions for all measurements. It appears that the damping loss factor obtained may be very sensitive to the method of installation of the Green Glue.

\section{Conclusions}

The sound insulation of double leaf cavity wooden stud gypsum plaster board walls with sound absorbing material in their wall cavities can be improved by increasing the damping loss factor of the gypsum plaster board walls. If the wall leaves are each composed of two sheets of gypsum plaster board, this increase in damping can be obtained by gluing the gypsum plaster board walls together with viscoelastic glue such as Green Glue noise proofing compound or QuietGlue Pro. It appears that the damping loss factor may be very sensitive to the method of installation of the viscoelastic glue.

\section{References}

[1] J.L. Davy, The improvement of a simple theoretical model for the prediction of the sound insulation of double leaf walls, Journal of the Acoustical Society of America, 127 (2010) 841-849.

[2] J.L. Davy, Sound transmission of cavity walls due to structure borne transmission via point and line connections, Journal of the Acoustical Society of America, 132 (2012) 814821.

[3] Orfield Laboratories Inc, Report numbers OL05-0414, OL05-1035, OL05-1049, OL051050, OL05-1059, OL06-0910, OL08-1102, OL08-1103, OL10-0841, OL11-0306, OL110307, Orfield Laboratories Inc, Minneapolis, USA.

[4] Serious Materials, QuietGlue Pro versus Green Glue, 2011.

[5] ASTM, ASTM E 90-04 Standard Test Method for Laboratory Measurement of Airborne Sound Transmission Loss of Building Partitions and Elements, ASTM International, West Conshohocken, USA, 2004.

[6] ISO, ISO 15186-1:2000(E), Acoustics - Measurement of sound insulation in buildings and of building elements using sound intensity -- Part 1: Laboratory measurements, International Organisation for Standardardization, Geneva, Switzerland, 2000. 
[7] I. Sabourin, S. Schoenwald, J.-G. Richter, B. Zeitler, Sound transmission loss improvement by a viscoelastic material used in a constrained layer damping system, in: Acoustics Week in Canada 2011, Canadian Acoustical Association, Quebec City, 2011, pp. $1-2$.

[8] J.L. Davy, Predicting the sound insulation of single leaf walls - extension of Cremer's model, Journal of the Acoustical Society of America, 126 (2009) 1871-1877.

[9] J.-G. Richter, B. Zeitler, I. Sabourin, S. Schoenwald, Comparison of different methods to measure structural damping, in: Acoustics Week in Canada 2011, Canadian Acoustical Association, Quebec City, 2011, pp. 54-55. 